\title{
The Aqueous Extract of Dacryodes edulis (Burseraceae) Leaves Inhibits Cell Proliferation Induced by Estradiol on the Uterus and Vagina of Ovariectomized Female Wistar Rats
}

\author{
Marius Trésor Wego Kamgaing, Marie Alfrede Mvondo, Sylviane Laure Poualeu Kamani (D), \\ Stéphane Minko Essono, and Sylvie Lea Wansi Ngnokam $\mathbb{D}$
}

Department of Animal Biology, Faculty of Science, University of Dschang, P. O. Box 67 Dschang, Dschang, Cameroon

Correspondence should be addressed to Sylvie Lea Wansi Ngnokam; wansylvie@yahoo.fr

Received 27 May 2020; Revised 13 October 2020; Accepted 10 November 2020; Published 21 November 2020

Academic Editor: Abdelhakim Bouyahya

Copyright (c) 2020 Marius Trésor Wego Kamgaing et al. This is an open access article distributed under the Creative Commons Attribution License, which permits unrestricted use, distribution, and reproduction in any medium, provided the original work is properly cited.

\begin{abstract}
Proliferation is a cellular process strongly linked to the genesis of cancer. Natural substances with antiproliferative activities are currently potential alternatives in the treatment of cancers. Dacryodes edulis, for instance, is a medicinal plant traditionally used in the treatment of cancer. Scientific studies have reported the antioxidant activity of this plant. In addition, the presence of prostate cancer chemopreventive polyphenols was reported in D. edulis extracts. Therefore, this study was aimed to evaluate the effects of the aqueous extract of $D$. edulis leaves on cell proliferation induced by estradiol in ovariectomized female Wistar rats. In this regard, ovariectomized (OVX) rats were cotreated with estradiol valerate $\left(\mathrm{E}_{2} \mathrm{~V}\right)(0.75 \mathrm{mg} / \mathrm{kg})$ and the aqueous extract of D. edulis leaves. Control groups received either the vehicle (sham-operated animals and the OVX control), $\mathrm{E}_{2} \mathrm{~V}(0.75 \mathrm{mg} / \mathrm{kg})$ only, or $\mathrm{E}_{2} \mathrm{~V}$ $(0.75 \mathrm{mg} / \mathrm{kg})$ and tamoxifen $(10 \mathrm{mg} / \mathrm{kg})$. Treatments were administered orally for 3 consecutive days, and animals were sacrificed thereafter. Epithelial heights of the uterus and vagina were assessed. Uterine levels of total cholesterol and estradiol were determined as well. Results showed that the aqueous extract of $D$. edulis leaves reversed the effects of estradiol as it reduced uterine weight $(p<0.05)$, uterine $(p<0.05)$, and vaginal $(p<0.001)$ epithelium heights. This antiproliferative effect of $D$. edulis was associated with reduced tissue (uterine) levels of estradiol $(p<0.001)$. These results suggest that the aqueous extract of $D$. edulis leaves could be a potential alternative treatment for proliferation-related diseases.
\end{abstract}

\section{Introduction}

Steroid hormones play an important role in regulating proliferation and protein synthesis of target cells. Estrogens particularly are known to stimulate a variety of biosynthetic processes, such as those of the breast and the uterus. In addition, nonsteroidal antiestrogens were found to antagonize many of the actions of estrogens through competitive estrogen receptor (ER) binding, inhibition of aromatase activity, and steroidogenesis $[1,2]$. These antiestrogenic mechanisms could help reduce estrogenic response such as cell proliferation. Estrogen activities are mediated by two main isoforms of intracellular estrogen receptors: ER $\alpha$ and $\operatorname{ER} \beta[3,4] . \mathrm{ER} \alpha$ is expressed in about $75 \%$ of diagnosed breast tumors [5], which can thus be treated with agents targeting estrogen-mediated signaling, such as antiestrogens $[6,7]$. Estradiol has been recognized as the main hormone that stimulates the growth and development of cancer [8], especially estrogen-dependent cancers. They are the most prevalent hormone-related cancers in the world (50-80\%) [9]. The introduction of adjuvant systemic therapy led to a significant improvement in postsurgical survival and a reduction in disease relapse, especially in women with earlydiagnosed breast cancer and with positive ER tumors, who may receive endocrine therapy alone or in combination with cytotoxic therapy [10]. However, the use of these modern treatments was associated with substantial side effects $[11,12]$ and frequent recurrences [13]. Nowadays, the use of 
natural medicines as alternative treatments for cancer has greatly increased. The literature mentions the role of phytoestrogens in the treatment of breast cancer $[14,15]$. Indeed, phytoestrogens were found capable of inducing biological responses, which may be able to modulate the actions of endogenous estrogens [16] through mechanisms including ER modulation, aromatase inhibition, antiangiogenesis, inhibition of hormone action, and modulation of hormone production $[14,17]$. In order to elaborate effective strategies to control cell proliferation-related diseases such as estrogen-dependent cancers, research is increasingly focused on herbal medicines with traditionally reported anticancer properties and/or scientific evidence of antioxidant properties; as oxidative stress was found to promote cell proliferation [18-20] and to contribute to the initiation and progression of cancer [21].

Dacryodes edulis (Burseraceae) is a fruit tree widely spread in Cameroon. Its fruits are edible; meanwhile, the bark, leaves, stems, and roots are used as local medicine against some diseases such as anemia, dysentery, malaria, hypertension, cardiovascular diseases, and cancer [22-24]. The literature reports that extracts of fruits and leaves of $D$. edulis displayed antioxidant activities in vitro and in vivo, respectively $[25,26]$. Phytochemical analysis performed on the aqueous extract of the stem bark and the fruitcake of this plant revealed the presence of secondary metabolites such as phenols, flavonoids, flavonols, and alkaloids [23, 24]. These compounds were reported to display antiproliferative activities in vitro $[26,27]$. However, no scientific study reporting the in vivo antiproliferative effects of this plant was performed before. The present study therefore aimed at evaluating the ability of the aqueous extract of $D$. edulis leaves to inhibit cell proliferation induced by estradiol in ovariectomized rats. This effect was investigated on the uterus and vagina as both tissues are primary estrogen targets that rapidly respond to estradiol stimulation following a 3-day treatment in rats [28]. Qualitative and quantitative phytochemical analyses of this extract were performed to highlight bioactive compounds having antiestrogenic and antiproliferative activities. Uterine levels of total cholesterol and estradiol were assessed to illustrate the probable mechanism of action of the aqueous extract of D. edulis leaves.

\section{Material and Methods}

2.1. Chemicals. All the reagents were obtained commercially. Folin-Ciocalteu reagent, sodium carbonate, aluminium chloride, sodium nitrite, sodium hydroxide, sodium acetate, gallic acid, quercetin, chloroform, sodium hydroxide, chloric acid, iron chloride, acetic anhydride, sulfuric acid, and Mayer's reagent were purchased from SigmaAldrich (St. Louis, USA). Tamoxifen citrate was purchased from EuroGenerics (EG) Lab, Egis Pharmaceuticals Ltd, 1106 Budapest, Hungary. Estradiol valerate (Progynova $2 \mathrm{mg}$ ) was purchased from Bayer Pharma AG (Berlin, Germany). Diagnostic kits used for the estimation of total cholesterol were procured from Sigma-Aldrich (Stanford, Germany). All chemicals and reagents were of analytical grade.

\subsection{Plant Collection and Preparation of the Aqueous Extract}

2.2.1. Plant Collection and Authentication. The leaves of D. edulis were collected in August 2018 at Dschang, the West Region of Cameroon, and authenticated in comparison with the botanical sample of Letouzez R. N. 4685 by Eric Ngansop Tchatchouang, a botanist at the Cameroon National Herbarium, where a voucher specimen has been deposited under the number 5552 SRF/CAM (YA). After collection, the leaves were shade-dried, then powdered with a mechanical grinder, passing through a sieve (11.2 mm with 7/16 standard mesh), and stored in an air-tight container at room temperature.

\subsubsection{Preparation of the Aqueous Extract and Determination} of the Doses Tested. The extract was prepared following the recommendations of previous studies realized on the stem bark of this plant for phytochemical screening and medicinal potentials $[23,24]$. Powdered leaves $(300 \mathrm{~g})$ of $D$. edulis were macerated in $3 \mathrm{~L}$ of distilled water for $48 \mathrm{~h}$ at room temperature. The supernatant was then filtered with Whatman paper no. 4 and dried in an oven at $40^{\circ} \mathrm{C}$ for two days. Twenty-nine grams (yield: $9.67 \%$ ) of the aqueous extract was obtained and stored in an air-tight container at $-20^{\circ} \mathrm{C}$ until use.

Four doses of this extract were administered to animals: 25, 50, 100, and $200 \mathrm{mg} / \mathrm{kg}$ BW. These doses have been extrapolated from previous studies realized on rats $[25,29]$. Uhunmwangho and Omoregie [25] reported that the oral administration of $50 \mathrm{mg} / \mathrm{kg}$ of the methanol extract of D. edulis fruit induced antioxidant activity in rats. This dose was therefore divided by 2 to obtain the lowest dose of $25 \mathrm{mg} / \mathrm{kg}$. The doses of 100 and $200 \mathrm{mg} / \mathrm{kg}$ were obtained by multiplying $50 \mathrm{mg} / \mathrm{kg}$ by 2 and 4 , respectively.

\subsection{Qualitative and Quantitative Analyses on Phytochemical} Constituents. The qualitative analysis of phytochemical constituents was conducted following the methods described by Harbone [30] in a book entitled: "A guide to modern techniques of plant analysis". The quantitative determination of total phenols, total flavonoids, and flavonol content was evaluated using the methods described by Ramde-Tiendrebeogo et al. [31], Chang et al. [32], and Almaraz-Abarca et al. [33], respectively. These phytochemical analyses were based on the appearance of different colours and the formation of precipitates or products in the final solution.

2.3.1. Analysis of Alkaloids. A total of 0.1 gram of the aqueous extract was introduced in a test tube in the presence of $3 \mathrm{~mL}$ of hydrochloric acid $(50 \% \mathrm{~V} / \mathrm{V})$. The solution was treated with 3 drops of Mayer's reagent, and the formation of a white precipitate indicated the presence of alkaloids [30].

2.3.2. Analysis of Phenols. For phenol determination, 0.1 gram of the aqueous extract was solubilized in $3 \mathrm{~mL}$ of ethanol. The solution was treated with 3 drops of iron 
chloride III $10 \%(\mathrm{~V} / \mathrm{V})$, and the appearance of a blue-violet color indicated the presence of phenols [30].

2.3.3. Analysis of Flavonoids. Few drops of $1 \% \mathrm{NH}_{3}$ solution was added to 0.1 gram of the aqueous extract contained in a test tube. The appearance of a yellow color indicated the presence of flavonoid compounds [30].

2.3.4. Analysis of Sterol and Triterpenoids. A total of 0.1 gram of the aqueous extract was solubilized in $3 \mathrm{~mL}$ of chloroform. A volume of $3 \mathrm{~mL}$ of acetic anhydride has been added, and the solution was frozen for $3 \mathrm{~min}$. One drop of concentrated sulfuric acid was added. The presence of triterpenoid was confirmed by the appearance of a red-violated color, while that of sterols was indicated by a successive appearance of blue, green, red, and orange colors [30].

2.3.5. Analysis of Tannins. For tannins identification, 0.1 gram of the aqueous extract was boiled in $20 \mathrm{~mL}$ of distilled water in a test tube and then filtered. The filtration method used here is the normal method, which includes a conical flask and filter paper. Three drops of $0.1 \% \mathrm{FeCl}_{2}$ were added to the filtered samples and observed for a brownish green or a blue black color, which indicates the presence of tannins [30].

2.3.6. Analysis of Saponins. Two grams of powdered samples of the plant was boiled together with $20 \mathrm{~mL}$ of distilled water in a water bath and filtered. A volume of $10 \mathrm{~mL}$ of the filtered sample was mixed with $5 \mathrm{~mL}$ of distilled water in a test tube and shaken vigorously to obtain a stable persistent froth. The frothing was then mixed with three drops of olive oil and observed for the formation of emulsion, which indicates the presence of saponins [30].

2.3.7. Analysis of Anthocyanins. For the identification of anthocyanins, 0.1 gram of the aqueous extract was boiled in $5 \mathrm{~mL}$ of $\mathrm{HCl}(1 \% \mathrm{~V} / \mathrm{V})$. The presence of anthocyanins was traduced by the appearance of an orange color [30].

2.3.8. Analysis of Anthraquinones. A volume of $4 \mathrm{~mL}$ of ether-chloroform $(1: 1 \mathrm{v} / \mathrm{v})$ solution was added to 0.1 gram of the aqueous extract. The solution was treated with $4 \mathrm{~mL}$ of sodium hydroxide $10 \%(\mathrm{P} / \mathrm{V})$. Anthraquinones were identified by the appearance of a red color [30].

2.3.9. Quantitative Analysis of Total Phenols. Total phenolic content in the extract was determined by the modified Folin-Ciocalteu method [31]. The reaction mixture consisted of $200 \mu \mathrm{L}$ of extract, $200 \mu \mathrm{L}$ of $2 \mathrm{~N}$ Folin-Ciocalteu reagent, and $400 \mu \mathrm{L}$ of $20 \%$ sodium carbonate solution. The mixture was stirred and incubated in a water bath at $40^{\circ} \mathrm{C}$ for 20 minutes. The experiment was carried out in triplicate. The absorbance was read at $760 \mathrm{~nm}$. Total phenolic content was expressed as milligram gallic acid equivalent/gram extract
(mgGAE/gE) using the equation obtained from a calibration curve of gallic acid $\left(y=1877.9 x+0.1142 ; R^{2}=0.9989\right)$.

2.3.10. Quantitative Analysis of Total Flavonoids. Total flavonoids were estimated using the aluminium colorimetric method described by Chang et al. [32]. In brief, $1500 \mu \mathrm{L}$ of distilled water and $30 \mu \mathrm{L}$ of sodium nitrite at $5 \%$ were added to $100 \mu \mathrm{L}$ of the extract. After $5 \mathrm{~min}$ of incubation at room temperature, $30 \mu \mathrm{L}$ of aluminium chloride $(10 \%)$ and $200 \mu \mathrm{L}$ of sodium hydroxide $(1 \mathrm{M})$ were added to the mixture. The experiment was carried out in triplicate. The absorbance was measured at $510 \mathrm{~nm}$. Total flavonoid content was calculated as milligram quercetin equivalent/gram extract (mgQE/gE) using the equation obtained from the calibration curve $\left(y=300.75 x+0.0897 ; R^{2}=0.9956\right)$.

\subsubsection{Quantitative Analysis of Flavonol Content.} Flavonol content was determined according to the method of Almaraz-Abarca et al. [33]. In test tubes containing $1280 \mu \mathrm{L}$ of distilled water, $40 \mu \mathrm{L}$ of extract $(2 \mathrm{mg} / \mathrm{ml}), 40 \mu \mathrm{L}$ of aluminium chloride (20\%), and $40 \mu \mathrm{L}$ of sodium acetate (5\%) were added. The experiment was carried out in triplicate. The absorbance was measured after 30 minutes at $415 \mathrm{~nm}$. The flavonol content was calculated as milligram quercetin equivalent/gram extract (mgQE/gE) using the equation obtained from the calibration curve $(y=0.1872 \mathrm{x}$; $\left.R^{2}=0.9734\right)$.

2.4. Experimental Animals. Juvenile female Wistar rats aged 2 months (100-120 g) were obtained from the breeding facility of the Research Unit of Animal Physiology and Phytopharmacology, University of Dschang (Cameroon). They were bred and kept under a standard soy-free rat diet in order to eliminate exposure to exogenous estrogenic compounds. All the animals were given free access to diet and water ad libitum. Animal handling and in vivo experiments were carried out after the approval of the research proposal by the scientific committee of the Department of Animal Biology, University of Dschang, in conformity with the European community guidelines EEC Council Direction 2010/63/EU of 22 September 2010 [34].

2.5. Study Design. Forty-two female Wistar rats were ovariectomized (OVX) as described by Mvondo et al. [35], and six other were subjected to a simple laparotomy (shamoperated). After two weeks of postsurgical treatments, the animals were randomly distributed into 8 groups of 6 animals each as follows:

(1) SHAM: sham-operated animals, receiving distilled water $(10 \mathrm{ml} / \mathrm{kg})$

(2) $[\mathrm{OVX}]$ : Ovariectomized (ovx) rats receiving distilled water $(10 \mathrm{ml} / \mathrm{kg})$

(3) $\left[\mathrm{OVX}+\mathrm{E}_{2} \mathrm{~V}\right]$ : ovx rats receiving estradiol valerate $(0.75 \mathrm{mg} / \mathrm{kg})$ 
(4) $\left[\mathrm{OVX}+\mathrm{E}_{2} \mathrm{~V}+\mathrm{TAM}\right]$ : ovx rats receiving estradiol valerate $(0.75 \mathrm{mg} / \mathrm{kg})$ and tamoxifen $(10 \mathrm{mg} / \mathrm{kg})$

(5) $\left[\mathrm{OVX}+\mathrm{E}_{2} \mathrm{~V}+\mathrm{AE} 25\right]$ : ovx rats receiving estradiol valerate $(0.75 \mathrm{mg} / \mathrm{kg})$ and the aqueous extract of D. edulis leaves at the dose of $25 \mathrm{mg} / \mathrm{kg}$

(6) $\left[\mathrm{OVX}+\mathrm{E}_{2} \mathrm{~V}+\mathrm{AE} 50\right]$ : ovx rats receiving estradiol valerate $(0.75 \mathrm{mg} / \mathrm{kg})$ and the aqueous extract of D. edulis leaves at the dose of $50 \mathrm{mg} / \mathrm{kg}$

(7) $[\mathrm{OVX}+\mathrm{E} 2 \mathrm{~V}+\mathrm{AE} 100]$ : ovx rats receiving estradiol valerate $(0.75 \mathrm{mg} / \mathrm{kg})$ and the aqueous extract of $D$. edulis leaves at the dose of $100 \mathrm{mg} / \mathrm{kg}$

(8) $\left[\mathrm{OVX}+\mathrm{E}_{2} \mathrm{~V}+\mathrm{AE} 200\right]$ : ovx rats receiving estradiol valerate $(0.75 \mathrm{mg} / \mathrm{kg})$ and the aqueous extract of D. edulis leaves at the dose of $200 \mathrm{mg} / \mathrm{kg}$

Animals were treated with the suboptimal dose of estradiol valerate $(0.75 \mathrm{mg} / \mathrm{kg})$ in reference to a previous work reporting the antiestrogenic effects of a medicinal plant [36]. The dose of tamoxifen $(10 \mathrm{mg} / \mathrm{kg})$ was chosen in reference to a previous study reporting the antiestrogenic activity of tamoxifen on breast cancer cells [37, 38]. Treatments were given orally for 3 consecutive days, and the animals were sacrificed thereafter under anesthesia (10 $\mathrm{mg} / \mathrm{kg}$ diazepam and $50 \mathrm{mg} / \mathrm{kg}$ ketamine). The uterus and vagina were collected, free from fat tissues and weighed (only the uterus). The left horn of the uterus was homogenized and centrifuged at $3000 \mathrm{rpm}$ for 15 minutes at $5^{\circ} \mathrm{C}$. The resulting supernatant was collected and stored at $-20^{\circ} \mathrm{C}$ for biochemical analysis. The right horn of the uterus and the entire vagina were fixed in $10 \%$ formalin for histological analysis.

2.6. Biochemical Analysis. Uterine total cholesterol levels were determined in each animal by an enzymatic method using commercial standard diagnostic kits purchased from SIGMA Diagnostics Ltd (1238 Budapest, Hungary).

Uterine estradiol levels were assessed by the ELISA test using a reagent kit (Mouse/Rat Estradiol ELISA) purchased from Calbiotech (El Cajon, California, USA). The absorbance of calibrators and specimen was determined using an ELISA microplate reader, the Multiskan ascent plate reader, purchased from MTX Lab Systems, Inc. (Bradenton, USA). The concentration $(\mathrm{mIU} / \mathrm{mL})$ was evaluated by means of a calibration curve established from the calibrators supplied with the kits.

2.7. Histological Analysis. Uterus and vagina epithelial heights were assessed from $5 \mu \mathrm{m}$ sections of paraffinembedded uterine and vaginal tissues. Following the hematoxylin-eosin staining, epithelial heights were assessed on microphotographs using a computer connected to a light microscope provided by Olympus (Tokyo, Japan) where the image was transferred and analyzed with the Image J1.3 software.

2.8. Statistical Analysis. Data are expressed as mean\pm standard error of the mean (SEM). Means were compared using one-way analysis of variance (ANOVA) followed by the Tukey post hoc test. GraphPad Prism, version 5.03, (for pharmacological tests) and Microsoft Excel 2007 (for phytochemical analysis) were used, and differences were considered significant at $p<0.05$.

\section{Results}

3.1. Qualitative Phytochemical Analysis of the Aqueous Extract of $D$. edulis Leaves. Table 1 presents the phytochemical composition of the aqueous extract of $D$. edulis leaves. According to this table, the aqueous extract of D. edulis contains alkaloids, phenols, flavonoids, triterpenoids, tannins, saponins, anthocyanins, and anthraquinones. Sterols were not detectable in the extract.

3.2. Quantitative Phytochemical Analysis of the Aqueous Extract of D. edulis Leaves. The concentrations of total phenols, flavonoids, and flavonols in the aqueous extract of D. edulis leaves are presented in Figure 1. This figure shows that the aqueous extract of $D$. edulis contains a significant amount of total phenols ( $5.53 \pm 0.07 \mathrm{mgGAE} / \mathrm{gE})$, flavonoids $(2.42 \pm 0.28 \mathrm{mgQE} / \mathrm{gE})$, and flavonols $(1.17 \pm 0.12 \mathrm{mgQE} /$ $\mathrm{gE})$.

\subsection{Effects of Treatments on the Uterus}

3.3.1. Effects on Uterine Wet Weight and Histomorphology. (i) Effects on the uterine wet weight. Compared with the SHAM control group, the relative uterine wet weight of ovariectomized animals decreased by $63.75 \%(p<0.001)$ (Figure 2). Estradiol valerate $\left(\mathrm{E}_{2} \mathrm{~V}\right)$ inversed this effect of ovariectomy as it increased the uterine wet weight by $212.88 \%(p<0.001)$ compared with the OVX control. The coadministration of estradiol valerate with tamoxifen decreased the uterus relative weight by $32 \%(p<0.01)$, compared with the $\mathrm{OVX}+\mathrm{E}_{2} \mathrm{~V}$ group. At tested doses, the aqueous extract of $D$. edulis leaves also inhibited the trophic effect of $\mathrm{E}_{2} \mathrm{~V}$ by reducing the relative uterine wet weight compared with the $\mathrm{OVX}+\mathrm{E}_{2} \mathrm{~V}$ group.

(ii) Effects on the uterine histomorphology. The uterus of shamoperated animals was lined by a tall columnar epithelium (Figure 3(a)). The uterus of OVX animals presented a low cuboidal epithelium. Following treatment with estradiol valerate only, or in coadministration with tamoxifen, uterine epithelial cells were similar to those of sham-operated animals, but with a reduced thickness. The uterine epithelium of animals cotreated with estradiol valerate and the aqueous extract of D. edulis was similar to that of the OVX control group.

Figure 3(b) shows that ovariectomy decreased the uterine epithelial height by $57.14 \%(p<0.001)$ compared with the SHAM control group. The daily administration of estradiol valerate increased this parameter by $51 \%(p<0.05)$ compared with the OVX control. The coadministration of estradiol valerate with tamoxifen did not significantly affect the uterine epithelial height, which remained similar to that of the OVX $+\mathrm{E}_{2} \mathrm{~V}$ group. At tested doses, the aqueous extract of $D$. edulis leaves inhibited the tropic effect of estradiol 
TABLE 1: Qualitative phytochemical analysis of the aqueous extract of $D$. edulis leaves.

\begin{tabular}{lc}
\hline Phytochemicals & Qualitative remarks \\
\hline Alkaloids & + \\
Phenols & + \\
Flavonoids & + \\
Sterols & - \\
Triterpenoids & + \\
Tannins & + \\
Saponins & + \\
Anthocyanins & + \\
Anthraquinones & +
\end{tabular}

$+=$ detectable; $-=$ not detectable.

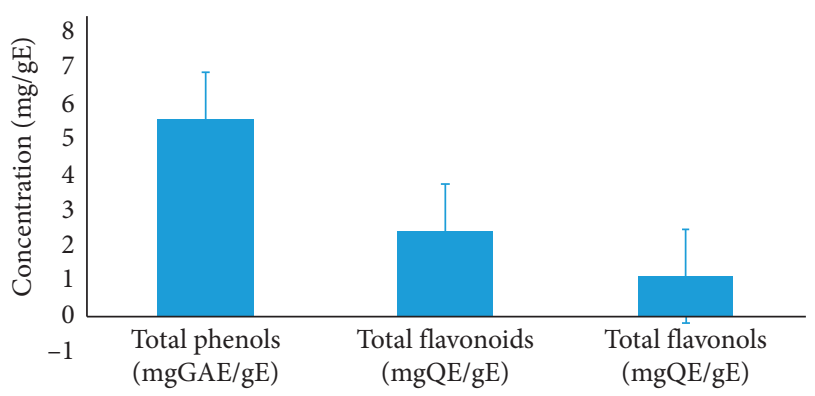

FIGURE 1: Quantitative analysis of phytochemical constituents of the leaves of $D$. edulis. GAE: gallic acid equivalent; QE: quercetin equivalent; E: extract.

valerate by reducing $(p<0.05)$ the uterine epithelial height, with significant effects at doses of $100(46.6 \%)$ and 200 (41.4\%) $\mathrm{mg} / \mathrm{kg}$, compared with the OVX $+\mathrm{E}_{2} \mathrm{~V}$ group.

\subsubsection{Effects on Uterine Levels of Cholesterol and Estradiol.} Compared with the SHAM control group, the uterine levels of cholesterol decreased by $29 \%$ in ovariectomized animals (Figure 4(a)). The oral administration of estradiol valerate inversed this effect of ovariectomy and increased this parameter by $99 \%(p<0.05)$, compared with the OVX control. The coadministration of estradiol valerate with tamoxifen increased uterine levels of cholesterol by $37 \%$, compared with the $\mathrm{OVX}+\mathrm{E}_{2} \mathrm{~V}$ group. The aqueous extract of $D$. edulis leaves further increased this parameter at tested doses, compared with the $\mathrm{OVX}+\mathrm{E}_{2} \mathrm{~V}$ group.

Uterine levels of estradiol reduced by $94 \%(p<0.001)$ in ovariectomized animals, compared with the SHAM control group. The daily administration of estradiol valerate inversed this effect of ovariectomy as it increased this parameter by $1052 \%(p<0.001)$, in comparison with the OVX control. The coadministration of estradiol valerate with tamoxifen reduced uterine levels of estradiol by $49.54 \%$ $(p<0.01)$, in comparison with the $\mathrm{OVX}+\mathrm{E}_{2} \mathrm{~V}$ group. A similar effect was observed in animals cotreated with $\mathrm{E}_{2} \mathrm{~V}$ and the aqueous extract of $D$. edulis leaves at tested doses $(25 \mathrm{mg} / \mathrm{kg}$ (90.1\% induction, $p<0.001), 50 \mathrm{mg} / \mathrm{kg}(41.11 \%$ induction, $\quad p<0.01), \quad 100 \mathrm{mg} / \mathrm{kg} \quad(75.13 \%$ induction, $p<0.001)$, and $200 \mathrm{mg} / \mathrm{kg}(90.5 \%$ induction, $p<0.001)$ ), compared with the OVX $+\mathrm{E}_{2} \mathrm{~V}$ group (Figure $4(\mathrm{~b})$ ).

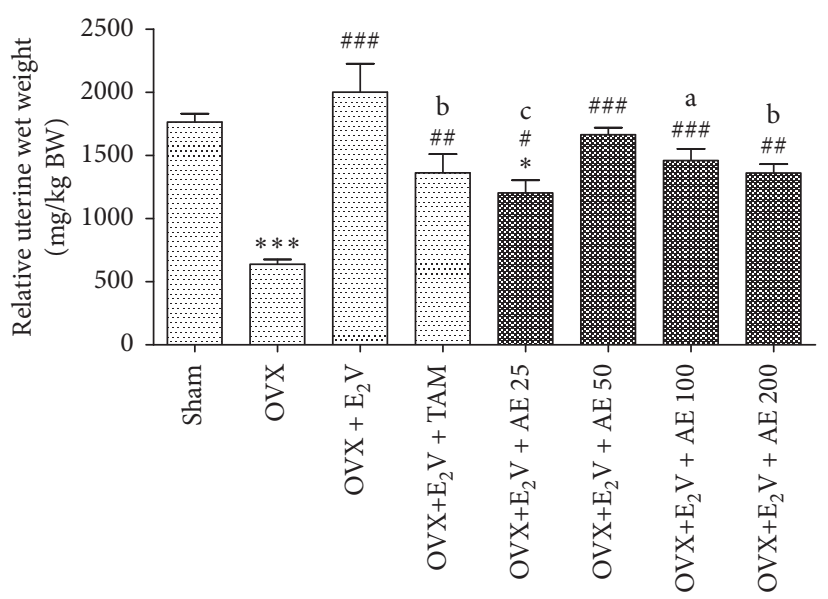

FIGURE 2: Effects of treatments on the relative uterine wet weight. SHAM: sham-operated animals; OVX: ovariectomized animals; $\mathrm{E}_{2} \mathrm{~V}$ : estradiol valerate; TAM: tamoxifen; $\mathrm{AE}$ : aqueous extract of D. edulis leaves. Data are presented as mean \pm S.E.M. $(n=6)$. ${ }^{*} p<0.05$ and ${ }^{* * *} p<0.001$ compared with SHAM; ${ }^{*} p<0.05$, \#\# $p<0.01$, and \#\# $p<0.001$ compared with OVX; and ${ }^{a} p<0.05$, ${ }^{b} p<0.01$, and ${ }^{c} p<0.001$ compared with $\mathrm{OVX}+\mathrm{E}_{2} \mathrm{~V}$.

\subsection{Effects of Treatments on the Histomorphology of the} Vagina. The vaginal epithelium of the SHAM group exhibited three layers arranged, from the basal membrane to the lumen, as follows: stratum germinativum, stratum granulosum, and stratum corneum. Following ovariectomy, the vaginal epithelium was reduced to a single layer, the stratum germinativum. Following treatment with estradiol valerate, the vaginal epithelium was similar to that of the SHAM control, with the only difference that this epithelium was smaller than that of the aforementioned control. The coadministration of estradiol valerate with tamoxifen or with the aqueous extract of $D$. edulis leaves moderated the effect of estradiol valerate as it reduced the thickness of the vaginal epithelium (Figure 5(a)).

Figure 5(b) shows that ovariectomy decreased the vagina epithelial height by $85.21 \%(p<0.001)$ compared with the SHAM control. Estradiol valerate inversed the effect of ovariectomy as it increased the vagina epithelial height by $185.29 \%(p<0.001)$ compared with the OVX control. Tamoxifen inhibited the effect of estradiol valerate as it reduced the vagina epithelial height by $90.62 \%(p<0.001)$, in comparison with the $\mathrm{OVX}+\mathrm{E}_{2} \mathrm{~V}$ group. The aqueous extract of $D$. edulis leaves induced the similar effect as it also decreased the vagina epithelial height at tested doses $(25 \mathrm{mg} / \mathrm{kg}$ ( $92.45 \%$ induction, $p<0.001), 50 \mathrm{mg} / \mathrm{kg}$ ( $89 \%$ induction, $p<0.001), 100 \mathrm{mg} / \mathrm{kg}(95.32 \%$ induction, $p<0.001)$, and $200 \mathrm{mg} / \mathrm{kg}(91.34 \%$ induction, $p<0.001))$, compared with the $\mathrm{OVX}+\mathrm{E}_{2} \mathrm{~V}$ group.

\section{Discussion}

Cell proliferation is the major precursor of cancer [18], such as estrogen-dependent cancers. These cancers are the most prevalent hormone-related cancers (50-80\%) [9], whose genesis is stimulated by estrogens. These hormones are 


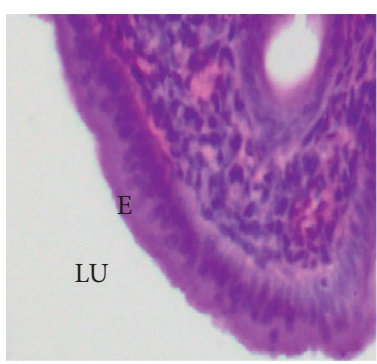

SHAM

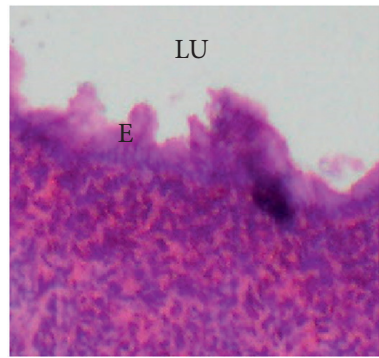

$\mathrm{OVX}+\mathrm{E}_{2} \mathrm{~V}+\mathrm{AE} 25$

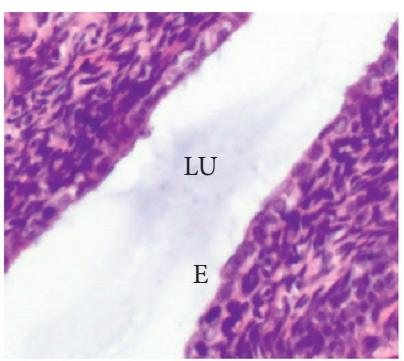

OvX

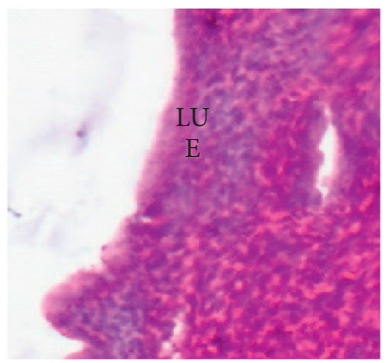

$\mathrm{OVX}+\mathrm{E}_{2} \mathrm{~V}+\mathrm{AE} 50$

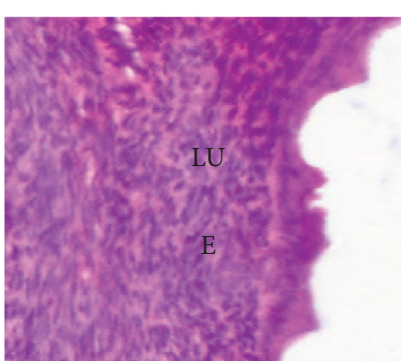

$\mathrm{OVX}+\mathrm{E}_{2} \mathrm{~V}$

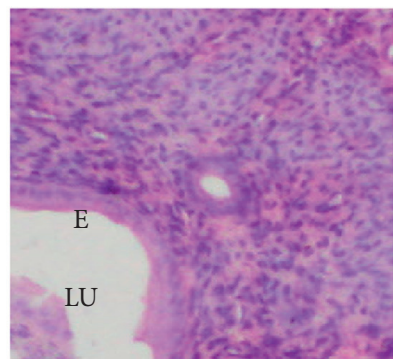

$\mathrm{OVX}+\mathrm{E}_{2} \mathrm{~V}+\mathrm{AE} 100$

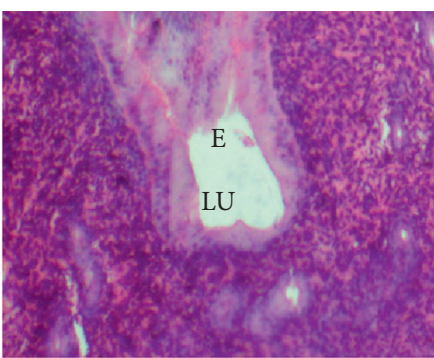

$\mathrm{OVX}+\mathrm{E}_{2} \mathrm{~V}+\mathrm{TAM}$

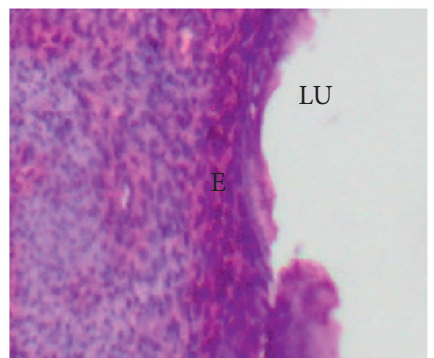

$\mathrm{OVX}+\mathrm{E}_{2} \mathrm{~V}+\mathrm{AE} 200$

(a)

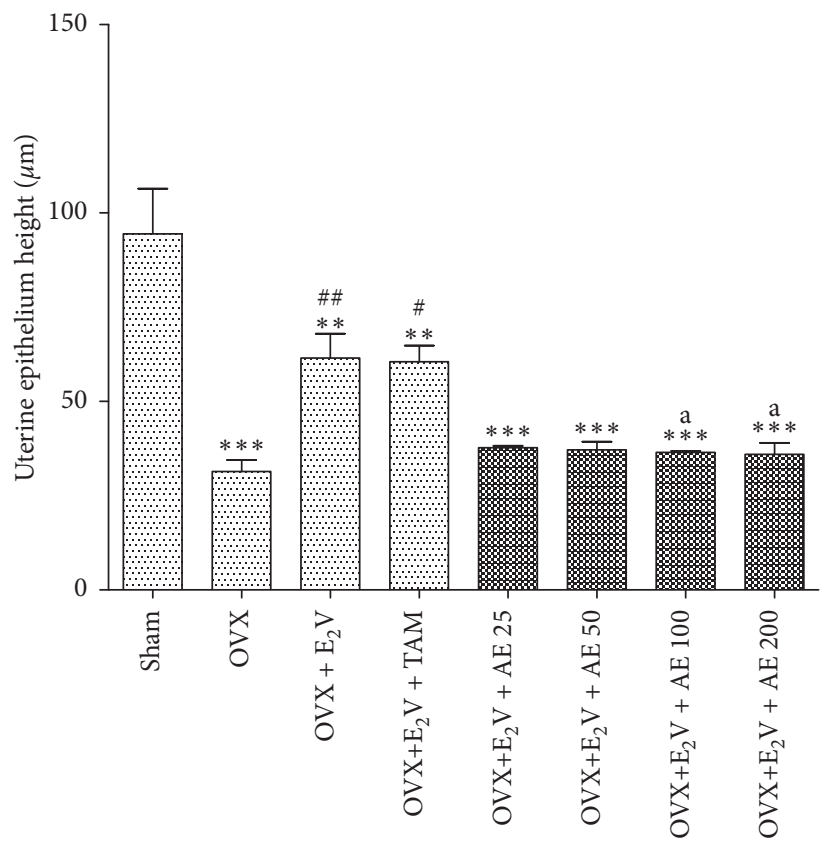

(b)

FIgURE 3: Microphotographs (H\&E 400x) (a) and epithelial height (b) of the uterus after 3 days of treatment. SHAM: sham-operated animals; OVX: ovariectomized animals; $\mathrm{E}_{2} \mathrm{~V}$ : estradiol valerate; TAM: tamoxifen; AE: aqueous extract of $D$. edulis leaves. Data are presented as mean \pm S.E.M. $(n=6) .{ }^{* *} p<0.01$ and ${ }^{* * *} p<0.001$ compared with SHAM; ${ }^{\#} p<0.05$ and ${ }^{\# \#} p<0.01$ compared with OVX; and ${ }^{a} p<0.05$ compared with $\mathrm{OVX}+\mathrm{E}_{2} \mathrm{~V}$. LU: lumen; E epithelium.

known to stimulate cell proliferation in estrogen-responsive targets such as the uterus and the vagina $[28,36,39]$. However, novel molecules are continuously being identified and developed from medicinal plants for better management of diseases in general and proliferative diseases in particular. These molecules in general are capable of inhibiting cell proliferation induced by estrogens [38]. To contribute to the quest for safer antiestrogenic and antiproliferative molecules, the in vivo antiestrogenic properties of the aqueous extract of $D$. edulis leaves were investigated.

Before evaluating the effects of the aqueous extract of D. edulis leaves on ovariectomized rats, a phytochemical analysis of that extract was performed. Results showed that the aqueous extract of $D$. edulis contains various secondary 


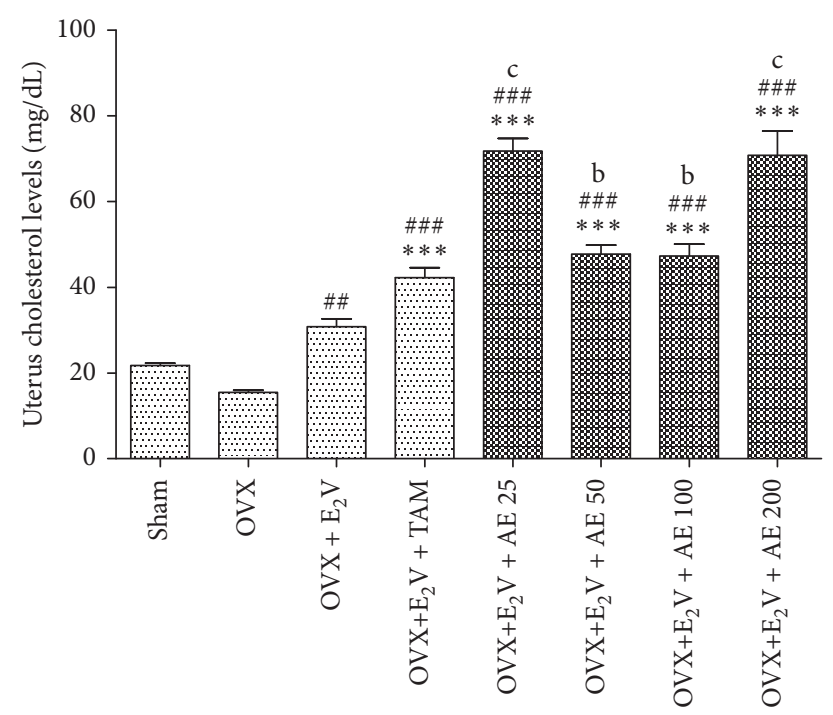

(a)

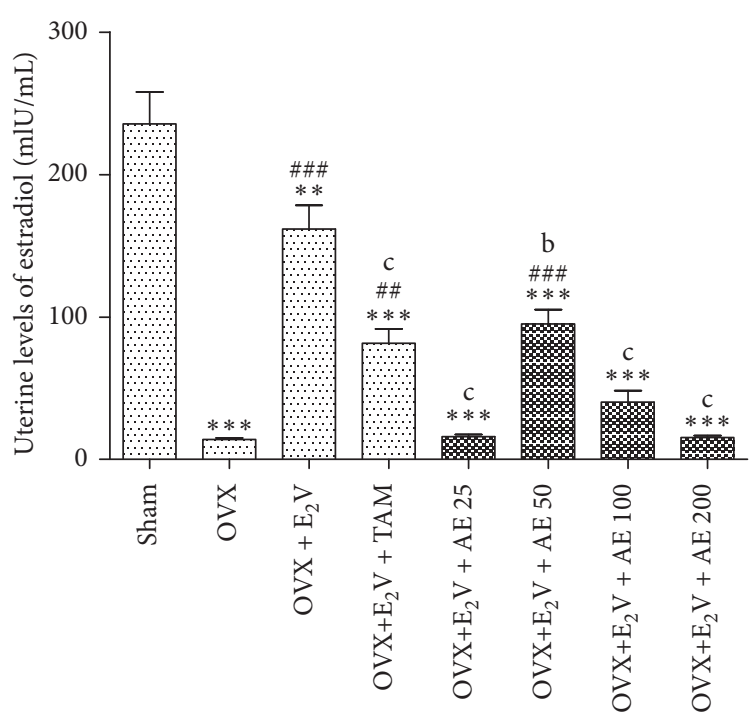

(b)

Figure 4: Effects of treatments on uterine levels of total cholesterol (a) and estradiol (b). SHAM: sham-operated animals; OVX: ovariectomized animals; $\mathrm{E}_{2} \mathrm{~V}$ : estradiol valerate; TAM: tamoxifen; AE: aqueous extract of D. edulis leaves. Data are presented as mean \pm S.E.M. $(n=6) .{ }^{* *} p<0.01$ and ${ }^{* * *} p<0.001$ compared with SHAM; ${ }^{\# \#} p<0.01$ and ${ }^{\# \# \#} p<0.001$ compared with OVX; and ${ }^{b} p<0.01$ and ${ }^{c} p<0.001$ compared with $\mathrm{OVX}+\mathrm{E}_{2} \mathrm{~V}$.

metabolites such as alkaloids, phenols, flavonoids, triterpenoids, tannins, saponins, anthocyanins, and anthraquinones. However, we observed the absence of sterols in this extract. These results are similar to those obtained by Ogboru et al. [23] in their research work in Nigeria in which they used the aqueous extract of the stem bark of $D$. edulis. In Ivory Coast, the fruitcake of $D$. edulis was also found to contain same groups of molecules [24]. However, contrary to these studies, sterols were not detectable in the aqueous extract of $D$. edulis leaves in the present research work. These results suggest that the harvest site and the part of the plant used have a direct impact on the presence of secondary metabolites in the plant. The quantitative analysis revealed that the aqueous extract of $D$. edulis leaves contains significant amounts of total phenols, flavonoids, and flavonols whose proportions were different (inferior) from those reported by Ogboru et al. [23] in Nigeria who worked with the stem bark and Ano-Aka et al. [24] in Ivory Coast who worked with the fruitcake of the same plant. These results suggest that the harvest site and the part of the plant used also have an impact on the amount of secondary metabolites in the plant. In addition, secondary metabolites such as anthraquinones, alkaloids, total phenols, flavonoids, and flavonols present in plants are reported to be antioxidant agents $[23,40,41]$, which may act in vivo to prevent oxidative damage to DNA, proteins, and lipids, thus reducing cell proliferation and by extension the risk of cancer development [42]. To this regard, the literature reports that polyphenols such as tannins, saponins, and triterpenoids are bioactive compounds that possess antiproliferative and anticancer properties [43-45]. Maria Graça et al. [46] and Amoussa et al. [41] reported the antioxidant activities of phenols, flavonoids, and flavonols. Indeed, oxidative stress was found to promote cell proliferation [18-20], thus contributing to the initiation and the progression of cancer [21]. Therefore, plant extracts containing secondary metabolites with antioxidant activities could be efficient against proliferation-related diseases.

Results from the in vivo study showed that ovariectomy induced a significant reduction of the uterus relative weight. This result is in accordance with a previous report indicating that after 14 days of ovariectomy, there is an important reduction of endogenous estrogens inducing uterus atrophy [47]. In addition, the administration of estradiol valerate for 3 consecutive days was found to increase the uterus relative weight and the uterus and vagina epithelial heights. The augmentation of the uterus and vagina epithelial heights was in accordance with the histomorphology of these organs, which showed the hypertrophy of uterine epithelial cells and the stratification of the vaginal epithelium. These results are in accordance with previous reports realized with estradiol valerate on ovariectomized rats [28, 47]. The uterotrophic effect of estrogen has been attributed to at least two events: water imbibition and/or cell proliferation [48, 49]. Moreover, the literature reports that these trophic and proliferative effects on the uterus and the vagina are mediated by the estrogen receptor alpha $(\mathrm{ER} \alpha)$ subtype $[50,51]$.

The daily coadministration of estradiol valerate with the aqueous extract of $D$. edulis leaves decreased the uterus relative weight and epithelial height of the uterus and the vagina. This effect could be due to the presence of flavonoids and flavonols in the aqueous extract of $D$. edulis leaves. Indeed, it has been shown that these compounds are capable of binding estrogen receptors [52,53] and competing with estrogens for binding ERs $[14,54]$. In addition, the literature reports that, in response to estrogen stimulation, uterine epithelial cells change from cubic to cylindrical $[26,55]$. The bilateral ablation of the ovaries leads to atrophy of the uterus 


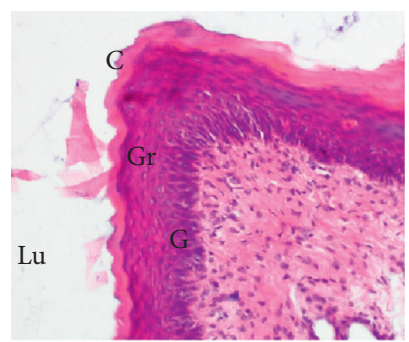

SHAM

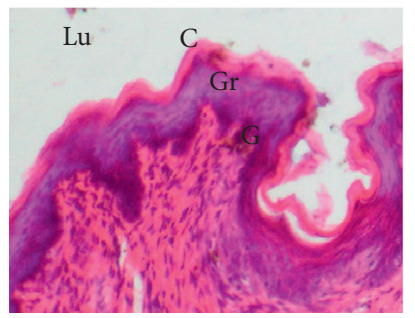

$\mathrm{OVX}+\mathrm{E}_{2} \mathrm{~V}+\mathrm{AE} 25$

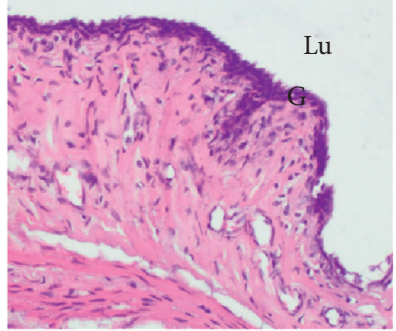

OVX

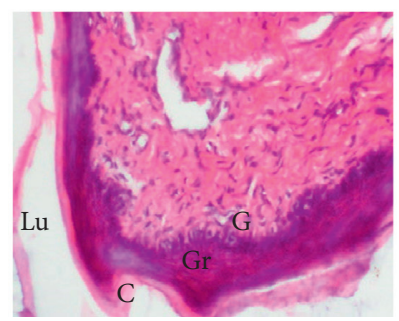

$\mathrm{OVX}+\mathrm{E}_{2} \mathrm{~V}+\mathrm{AE} 50$

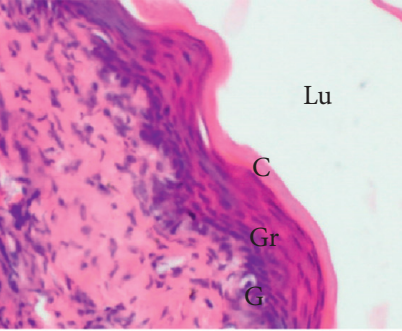

$\mathrm{OVX}+\mathrm{E}_{2} \mathrm{~V}$

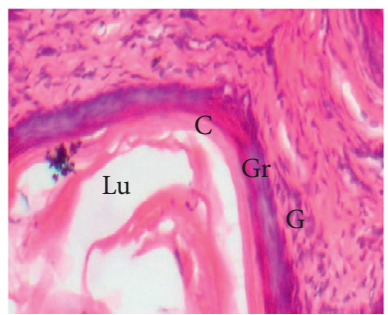

$\mathrm{OVX}+\mathrm{E}_{2} \mathrm{~V}+\mathrm{AE} 100$

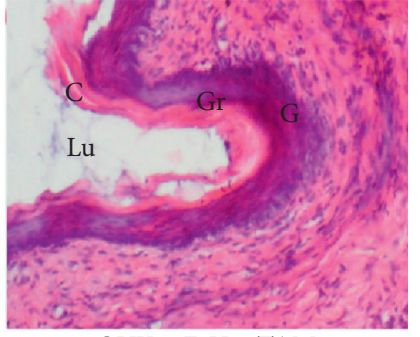

$\mathrm{OVX}+\mathrm{E}_{2} \mathrm{~V}+\mathrm{TAM}$

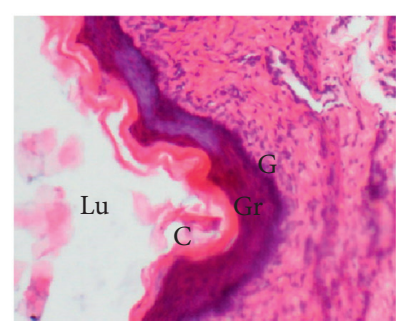

$\mathrm{OVX}+\mathrm{E}_{2} \mathrm{~V}+\mathrm{AE} 200$

(a)

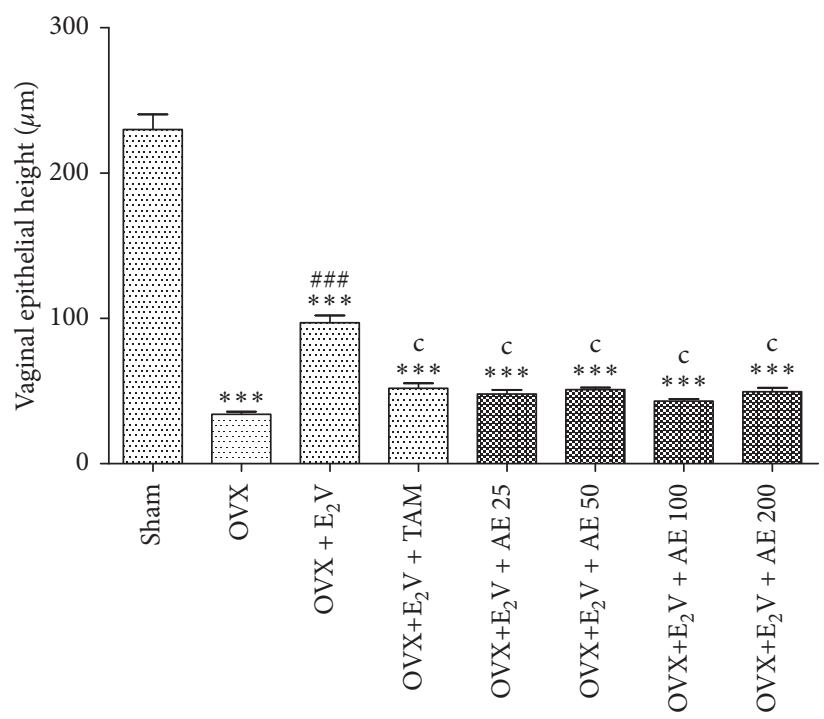

(b)

Figure 5: Microphotographs (H\&E 400x) (a) and epithelial height (b) of the vagina after 3 days of treatment. SHAM: sham-operated animals; OVX: ovariectomized animals; $\mathrm{E}_{2} \mathrm{~V}$ : estradiol valerate; TAM: tamoxifen; AE: aqueous extract of $D$. edulis leaves. Data from Figure 5(b) are presented as mean \pm S.E.M. $(n=6) .{ }^{* * *} p<0.001$ compared with SHAM; ${ }^{\# \# \#} p<0.001$ compared with OVX; and ${ }^{C} p<0.001$ compared with $\mathrm{OVX}+\mathrm{E}_{2} \mathrm{~V}$. Lu: lumen; G: stratum germinativum; Gr: stratum granulosum; C: stratum corneum.

epithelium made up of cubic cells [28,35]. Estradiol was also reported to be synthesized in situ in the uterus and to act in a paracrine manner to stimulate uterine growth $[35,56,57]$. In accordance with these literature data, our results showed that the uterine epithelium of ovariectomized animals (OVX) was made up of cubic cells, in comparison with SHAM control animals, in which this epithelium was rather cylindrical and might justify the reduction of the uterine epithelial height observed in the OVX group. The decrease of the uterine epithelium size in the OVX group was correlated with a decrease in uterine levels of total cholesterol. According to Zhao et al. [58], the novo synthesis of cholesterol in the uterus is stimulated by serum estradiol.
Therefore, the bilateral ovariectomy, which was found to decrease serum levels of estradiol [35], would have decreased uterine cholesterol levels by lowering circulating estrogen levels. Although the aqueous extract of $D$. edulis leaves did not reverse the effect of estradiol valerate on uterine cholesterol levels, it reduced its effect on uterine steroidogenesis as it decreased uterine levels of estradiol. These results suggest that the aqueous extract of $D$. edulis leaves could have inhibited at least one stage of steroidogenesis, leading to reduced levels of estradiol. In addition, the aforementioned extract could be endowed with hypercholesterolemic properties as it reduced the use of uterine cholesterol for steroidogenesis. This effect could be due to the presence of 
flavonoids and anthocyanins in this extract as these phytochemicals were reported to increase HDL-cholesterol levels $[59,60]$. Furthermore, the aqueous extract of $D$. edulis leaves induced hormesis-type responses on both cholesterol and estradiol levels in the uterus. Hormesis was defined as a dose-response relationship phenomenon characterized by low-dose inhibition and high-dose stimulation or inversely, leading to a U-shaped, an inverse U-shaped, or a J-shaped dose response [61, 62]. This dose-response revolution is not yet fully understood.

\section{Conclusion}

In summary, the present study showed that the aqueous extract of $D$. edulis leaves displayed antiproliferative activity as it inhibited the hypertrophy of uterine epithelial cells and the proliferation of vaginal epithelial cells, both events induced by estradiol valerate. This antiproliferative effect of the aforementioned extract may be mediated through the inhibition of tissue steroidogenesis as it decreased tissue levels of estradiol. These findings suggest that the aqueous extract of $D$. edulis leaves could be a promising alternative for the treatment of estrogen-dependent proliferative diseases.

\section{Data Availability}

Data used to support the findings of this study are available from the corresponding author upon request.

\section{Disclosure}

This research was performed at the Research Unit of Animal Physiology and Phytopharmacology of the University of Dschang, as part of the employment of the authors.

\section{Conflicts of Interest}

The authors declare that there are no conflicts of interest regarding the publication of this paper.

\section{Acknowledgments}

The authors are thankful to the Research Unit of Animal Physiology and Phytopharmacology of the University of Dschang for material support.

\section{References}

[1] B. S. Katzenellenbogen, H. S. Bhakoo, E. R. Ferguson et al., "Estrogen and antiestrogen action in reproductive tissues and tumors," Proceedings of the 1978 Laurentian Hormone Conference, vol. 35, pp. 259-300, 1979.

[2] S. Aitken and M. E. Lippman, "Effect of estrogens and antiestrogens on growth-regulatory enzymes in human breast cancer cells in tissue culture," Cancer Research, vol. 45, no. 4, pp. 1611-1620, 1985.

[3] J. Hatae, N. Takami, H. Lin, A. Honda, and R. Inoue, "17 $\beta$ Estradiol-induced enhancement of estrogen receptor biosynthesis via MAPK pathway in mouse skeletal muscle myoblasts," The Journal of Physiological Sciences, vol. 59, no. 3, pp. 181-190, 2009.
[4] AT. Vo and R. M. Millis, "Epigenetics and breast cancers," Obstetrics and Gynecology International, vol. 2012, p. 10, 2012.

[5] A. Popolo, L. A. Piccinelli, S Morello et al., "Antiproliferative activity of brown Cuban propolis extract on human breast cancer cells," Natural Product Communications, vol. 4, no. 12, pp. 1711-1716, 2009.

[6] S. Ali and R. C. Coombes, "Endocrine-responsive breast cancer and strategies for combating resistance," Nature Reviews Cancer, vol. 2, no. 2, pp. 101-112, 2002.

[7] C. W. Yde, K. B. Emdal, B. Guerra, and A. E. Lykkesfeldt, "NF $\kappa \mathrm{B}$ signaling is important for growth of antiestrogen resistant breast cancer cells," Breast Cancer Research and Treatment, vol. 135, no. 1, pp. 67-78, 2012.

[8] A. M. Ryan, M. Duong, L. Healy et al., "Obesity, metabolic syndrome and esophageal adenocarcinoma: epidemiology, etiology and new targets," Cancer Epidemiology, vol. 35, no. 4, pp. 309-319, 2011.

[9] R. Clarke, K. B. Liu, Z. Gu et al., "Antiestrogen resistance in breast cancer and the role of estrogen receptor signaling," Oncogene, vol. 22, no. 47, pp. 7316-7339, 2003.

[10] F. Lumachi, A. Brunello, M. Maruzzo, U. Basso, and S. Basso, "Treatment of estrogen receptor-positive breast cancer," Current Medicinal Chemistry, vol. 20, no. 5, pp. 596-604, 2013.

[11] H.-K. Chan and S. Ismail, "Side effects of chemotherapy among cancer patients in a malaysian general hospital: experiences, perceptions and informational needs from clinical pharmacists," Asian Pacific Journal of Cancer Prevention, vol. 15, no. 13, pp. 5305-5309, 2014.

[12] D. Umut, M. Benekli, S. Buyukberber, and U. Coskun, "Late side effects of cancer therapy," International Journal of Hematology and Oncology, vol. 4, no. 20, pp. 250-260, 2010.

[13] L. Joan, K. Warren, and R. Yabroff, "Challenges and opportunities in measuring cancer recurrence in the United States," JNCI Journal of the National Cancer Institute, vol. 107, no. 8, pp. 1-8, 2015.

[14] B. M. Collins-Burow, M. E. Burow, B. N. Duong, and J. A. McLachlan, "Estrogenic and antiestrogenic activities of flavonoid phytochemicals through estrogen receptor bindingdependent and -independent mechanisms," Nutrition and Cancer, vol. 38, no. 2, pp. 229-244, 2000.

[15] M. M. Liu, Y. Huang, and J. Wang, "Developing phytoestrogens for breast cancer prevention," Anti-cancer Agents in Medicinal Chemistry, vol. 12, no. 10, pp. 1306-1313, 2012.

[16] P. Sunita and S. Pattanayak, "Phytoestrogens in postmenopausal indications: a theoretical perspective," Pharmacognosy Reviews, vol. 5, no. 9, pp. 41-47, 2011.

[17] C. Sonnenschein and A. M. Soto, "An updated review of environmental estrogen and androgen mimics and antagonists," The Journal of Steroid Biochemistry and Molecular Biology, vol. 65, no. 1-6, pp. 143-150, 1998.

[18] S. Reuter, S. C. Gupta, M. M. Chaturvedi, and B. B. Aggarwal, "Oxidative stress, inflammation, and cancer: how are they linked?” Free Radical Biology and Medicine, vol. 49, no. 11, pp. 1603-1616, 2010.

[19] U. Udensi and P. Tchounwou, "Dual effect of oxydative stress on leukemia cancer induction and treatment," Journal of Experimental \& Clinical Cancer Research, vol. 33, p. 106, 2014.

[20] U. Udensi and P. Tchounwou, "Oxidative stress in prostate hyperplasia and carcinogenesis," Journal of Experimental \& Clinical Cancer Research, vol. 35, no. 1, p. 139, 2016.

[21] W.-S. Wu, "The signaling mechanism of ROS in tumor progression," Cancer and Metastasis Reviews, vol. 25, no. 4, pp. 695-705, 2006. 
[22] C. G. Grigoras, "Valorisation des fruits et des sous-produits de l'industrie de transformation des fruits par extraction des composés bioactifs," Université de l'Orléans, Orléans, France, Thèse, 2012.

[23] R. O. Ogboru, P. L. Okolie, and L. Agboje, "Phytochemical screening and medicinal potentials of the bark of dacryodes edulis (G. Don) HJ Lam," International Journal of Environmental Analytical Chemistry, vol. 2, no. 5, 2015.

[24] R. R. Ano Aka, N. E. Koffi, A. A. Adima, K. P. N’DA, and A. L. Anin, "Composition biochimique et phytochimique des tourteaux des fruits du safoutier (Dacryodes edulis) de Côte d'Ivoire," International Journal of Biological and Chemical Sciences, vol. 12, no. 6, pp. 2535-2546, 2018.

[25] ES. Uhunmwangho and E. S. Omoregie, "Comparative study of antioxidant activity and hepato-protective effect of extracts of Tetracarpidium conophorum and Dacryodes edulis on sodium arsenate exposed rats," Saudi Journal of Biomedical Research, vol. 3, no. 2, pp. 50-55, 2018.

[26] V. Kuete and T. Efferth, "Cameroonian medicinal plants: pharmacology and derived natural products," Frontiers in Pharmacology, vol. 123, no. 1, pp. 1-19, 2010.

[27] C. Voss, E. Eyol, and M. R. Berger, "Identification of potent anticancer activity in Ximenia Americana aqueous extracts used by African traditional medicine," Toxicology and Applied Pharmacology, vol. 211, pp. 177-187, 2005.

[28] M. A. Mvondo, D. Njamen, S. Tanee Fomum, and J. Wandji, "Effects of alpinumisoflavone and abyssinone V-4'-Methyl ether derived from Erythrina lysistemon (fabaceae) on the genital tract of ovariectomized female wistar rat," Phytotherapy Research, vol. 26, no. 7, pp. 1029-1036, 2012.

[29] S. Ufelle, E. Ukaejiofo, A. Peter, B. Eluke, S. Ghasi, and E. Neboh, "Potential haemopoietic effects of Dacryodes Edulis seeds extract in wistar rats," International Journal of Healthcare Sciences, vol. 3, no. 1, pp. 413-416, 2015.

[30] J. B. Harbone, Phytochemical Methods: A Guide to Modern Techniques of Plant Analysis, Springer Science and Business Media, Berlin, Heidelberg, 3rd edition, 1998.

[31] A. Ramde-Tiendrebeogo, A. Tibiri, A Hilou et al., "Antioxidative and antibacterial activities of phenolic compounds from Ficussue Forssk," International Journal of Biological and Chemical Sciences, vol. 6, no. 1, pp. 328-336, 2012.

[32] C. Chang, M. Yang, H. Wen, and J. Chern, "Estimation of total flavonoid content in propolis by two complementary colorimetric methods," Journal of Food and Drug Analysis, vol. 10, pp. 178-182, 2002.

[33] N. Almaraz-Abarca, M. da Graça Campos, J. A. Ávila-Reyes, N. Naranjo-Jiménez, J. Herrera Corral, and L. S. GonzálezValdez, "Antioxidant activity of polyphenolic extract of monofloral honeybee-collected pollen from mesquite (Prosopis juliflora, Leguminosae)," Journal of Food Composition and Analysis, vol. 20, no. 2, pp. 119-124, 2007.

[34] European Ethical Committee, "Council Directive 86/609EEC of November 1986 on the approximation of laws, regulations and administrative provisions of the Members States regarding the protection of animals used for experimental and other scientific purposes," Official Journal of the European Committee, vol. 358, pp. 1-29, 1986.

[35] M. A. Mvondo, N. S. Messongue Mbollo, and D. Njamen, "The ethanol extract of avocado [Persea americana Mill.(Lauraceae)] seeds reduced the hyperplastic effect of tamoxifen on uterine endometrium without changing its effect on the mammary gland," Advances in Traditional Medicine, vol. 4, pp. 1-10, 2020.

[36] T. N. Gueyo, M. A. Mvondo, S. Zingue et al., "Anthonotha macrophylla P. Beauv (Caesalpiniaceae) aqueous extract exhibits antiestrogenic effects in vitro and in vivo," Journal of Basic and Clinical Physiology and Pharmacology, vol. 31, no. 4, 2019.

[37] J. L. Borgna and H. Rochefort, "Hydroxylated metabolites of tamoxifen are formed in vivo and bound to estrogen receptor in target tissues," The Journal of Biological Chemistry, vol. 256, no. 2, pp. 859-868, 1981.

[38] Yu Yan, Q. Zhou, H. Yan, X. Bu, and W. Jia, “Antiestrogenic effect of 20 s-protopanaxadiol and its synergy with tamoxifen on breast cancer cells," American Cancer Society, vol. 109, no. 11, pp. 2374-2382, 2007.

[39] M. A. Mvondo, D. Njamen, S. T. Fomum, J. Wandji, and G. Vollmer, "A postmenopause-like model of ovariectomized Wistar rats to identify active principles of Erythrina lysistemon (Fabaceae)," Fitoterapia, vol. 82, no. 7, pp. 939-949, 2011.

[40] H. T. Soon, Y. L. Chung, H Hazrina et al., "Antidiabetic and antioxidant properties of alkaloids from Catharanthus roseus (L.) G. Don," Molecules, vol. 18, no. 8, pp. 9770-9784, 2013.

[41] A. M. O. Amoussa, S. Ambaliou, and L. Lagnika, "Antioxidant activity and total phenolic, flavonoid and flavonol contents of the bark extracts of Acacia ataxacantha," Journal of Pharmacognosy and Phytochemistry, vol. 4, no. 2, pp. 172-178, 2015.

[42] R. Babu Birudu and M. Jagadish Naik, "Anticancer properties of secondary metabolites of medicinal plants in carcinoma," British Biomedical Bulletin, vol. 2, pp. 359-370, 2014.

[43] M. J. Kulshreshtha, D. K. Kulshreshtha, and R. P. Rastogi, "Review article. The triterpenoids," Phytochemistry, vol. 11, pp. 2369-2381, 1992.

[44] B. Halliwell, "Effect of diet on cancer development: is oxidative DNA damage a biomarker?1,2 1This article is part of a series of reviews on "oxidative DNA damage and repair." the full list of papers may be found on the homepage of the journal. 2Guest Editor: miral Dizdaroglu," Free Radical Biology and Medicine, vol. 32, no. 10, pp. 968-974, 2002.

[45] A. Bishayee, S. Ahmed, N. Brankov, and M. Perloff, "Triterpenoids as potential agents for the chemoprevention and therapy of breast cancer," Frontiers in Bioscience, vol. 16, no. 1, pp. 980-996, 2011.

[46] M. Maria Graça, N. Susana, D. Susana Anahi, C. Ana Maria, and A. Maria Dulce, "Phenols, flavonoids and antioxidant activity of aqueous and methanolic extracts of propolis (Apis mellifera L.) from Algarve, South Portugal," Food Science and Technology, vol. 34, no. 1, pp. 16-23, 2014.

[47] S. Zingue, C. B. Magne Nde, T Michel et al., "Ethanolextracted Cameroonian propolis exerts estrogenic effects and alleviates hot flushes in ovariectomized Wistar rats," BMC Complementary and Alternative Medicine, vol. 17, p. 65, 2017.

[48] K. Yamasaki, M. Takeyoshi, M. Sawaki, N. Imatanaka, K. Shinoda, and M. Takatsuki, "Immature rat uterotrophic assay of 18 chemicals and Hershberger assay of 30 chemicals," Toxicology, vol. 183, no. 1-3, pp. 93-115, 2003.

[49] O. Takahashi, S. Oishi, M. Yoneyama, A. Ogata, and H. Kamimura, "Antiestrogenic effect of paradichlorobenzene in immature mice and rats," Archives of Toxicology, vol. 81, no. 7, pp. 505-517, 2007.

[50] J. F. Couse, S. W. Curtis, T. F. Washburn, E. M. Eddy, D. W. Schomberg, and K. S. Korach, "Disruption of the mouse oestrogen receptor gene: resulting phenotypes and experimental findings," Biochemical Society Transactions, vol. 23, no. 4, pp. 929-935, 1995.

[51] S. C. Hewitt, B. J. Deroo, K. Hansen et al., "Estrogen receptordependent genomic responses in the uterus mirror the biphasic 
physiological response to estrogen," Molecular Endocrinology, vol. 17, no. 10, pp. 2070-2083, 2003.

[52] D. C. Knight and J. A. Eden, "A review of the clinical effects of phytoestrogens," Obstetrics and Gynecology, vol. 87, no. 5, pp. 897-904, 1996.

[53] Y. T. Van der Schouw, M. J. De Kleijn, P. H. Peeters, and D. E. Grobbee, "Phytoestrogens and cardiovascular disease risk," Nutrition, Metabolism \& Cardiovascular Diseases, vol. 10, pp. 154-167, 2000.

[54] Y. M. Lee, J. B. Kim, J. H Bae et al., "Estrogen-like activity of aqueous extract from Agrimonia pilosa Ledeb. in MCF-7 cells," BMC Complementary and Alternative Medicine, vol. 12, p. 260, 2012.

[55] F. R. Westwood, "The female rat reproductive cycle: a practical histological guide to staging," Toxicologic Pathology, vol. 36, no. 3, pp. 375-384, 2008.

[56] K. Huhtinen, R. Desai, M. Ståhle et al., "Endometrial and endometriotic concentrations of estrone and estradiol are determined by local metabolism rather than circulating levels," The Journal of Clinical Endocrinology \& Metabolism, vol. 97, no. 11, pp. 4228-4235, 2012.

[57] G. Konings, L. Brentjens, B Delvoux et al., "Intracrine regulation of estrogen and other sex steroid levels in endometrium and non-gynecological tissues; pathology, physiology, and drug discovery," Frontiers in Pharmacology, vol. 9, p. 940, 2018.

[58] Y. Zhao, Q. Li, I. C. Bagchi, and M. K. Bagchi, "Estrogen stimulates de novo synthesis of cholesterol in mouse uterus during implantation," Biology of Reproduction, vol. 83, no. 1, p. 171, 2010.

[59] U. Subasini, S. Thenmozhi2, V. Venkateswaran, P. Pavani, S. Diwedi, and G. Victor Rajamanickam, "Phytochemical analysis and anti hyperlipidemic activity of nelumbo nucifera in male wistar rats," International Journal of Pharmacy Teaching \& Practices, vol. 5, no. 1, pp. 935-940, 2014.

[60] D. Wang, M. Xia, X. Yan et al., "Gut microbiota metabolism of anthocyanin promotes reverse cholesterol transport in mice via repressing miRNA-10b," Circulation Research, vol. 111, no. 8, pp. 967-981, 2012.

[61] E. J. Calabrese and L. A. Baldwin, "Hormesis: the dose-response revolution," Annual Review of Pharmacology and Toxicology, vol. 43, no. 1, pp. 175-197, 2003.

[62] E. J. Calabrese, "Hormesis: a revolution in toxicology, risk assessment and medicine," EMBO Reproduction, vol. 5, pp. 37-40, 2004. 